\title{
Three-Dimensional Culture of Human Embryonic Stem Cell Derived Hepatic Endoderm and Its Role in Bioartificial Liver Construction
}

\author{
Ruchi Sharma, Sebastian Greenhough, Claire N. Medine, and David C. Hay \\ Medical Research Council Centre for Regenerative Medicine, University of Edinburgh, 49 Little France Crescent, Edinburgh, \\ Scotland EH16 4SB, UK \\ Correspondence should be addressed to David C. Hay, davehay@talktalk.net
}

Received 7 September 2009; Accepted 3 December 2009

Academic Editor: James A. Ross

Copyright () 2010 Ruchi Sharma et al. This is an open access article distributed under the Creative Commons Attribution License, which permits unrestricted use, distribution, and reproduction in any medium, provided the original work is properly cited.

\begin{abstract}
The liver carries out a range of functions essential for bodily homeostasis. The impairment of liver functions has serious implications and is responsible for high rates of patient morbidity and mortality. Presently, liver transplantation remains the only effective treatment, but donor availability is a major limitation. Therefore, artificial and bioartificial liver devices have been developed to bridge patients to liver transplantation. Existing support devices improve hepatic encephalopathy to a certain extent; however their usage is associated with side effects. The major hindrance in the development of bioartificial liver devices and cellular therapies is the limited availability of human hepatocytes. Moreover, primary hepatocytes are difficult to maintain and lose hepatic identity and function over time even with sophisticated tissue culture media. To overcome this limitation, renewable cell sources are being explored. Human embryonic stem cells are one such cellular resource and have been shown to generate a reliable and reproducible supply of human hepatic endoderm. Therefore, the use of human embryonic stem cell-derived hepatic endoderm in combination with tissue engineering has the potential to pave the way for the development of novel bioartificial liver devices and predictive drug toxicity assays.
\end{abstract}

\section{Introduction}

The liver is the largest gland in the body and carries out a multitude of endocrine and exocrine functions [1]. The liver also possesses a remarkable regenerative capability; however, upon repeated injury it becomes progressively fibrosed and loses function. Existing treatments for patients with end stage liver diseases or acute liver failure are reliant upon liver cell or organ transplantation [2]. The mortality rate is as high as $80 \%$ in fulminant hepatic failure (FHF) in the absence of transplantation [3]. Approximately 6,000 liver transplant operations are performed in the United States (http://www.liverfoundation .org/education/info/transplant/) and about 600-700 in the UK every year (http://www.britishlivertrust.org.uk/home/ the-liver/liver-transplantation/a-history-of-liver-transplantation-and-current-statistics.aspx), but these numbers are limited by the availability of donor organs. In order to overcome this, the practice of living donor liver transplantation was introduced in 1989 [4]. A living donor is usually a blood relative who undergoes surgery in which a section of the liver is removed for transplantation into the recipient. Liver regeneration then occurs in both the donor and recipient over a period of 8-12 weeks. While promising, this is a complex, high risk procedure from which $20 \%$ of donors develop complications, and the associated ethical issues complicate its routine clinical deployment [5]. This has necessitated the exploration of alternative approaches to support human liver function during liver failure. One such approach receiving recent attention is the development of extracorporeal devices utilising hepatocytes to provide support during liver failure [6].

In addition to cell therapeutic approaches, another important aspect of human liver cell biology is the testing and safe development of new drugs, as the liver plays a central role in the metabolism of the majority of drugs [7]. Several 
in vitro human liver models have been developed including supersomes [8], microsomes, cytosol, S9 fraction, cell lines, liver slices and perfused lines. Although useful, these models suffer functional drawbacks, which affect drug attrition and therefore development costs $[8,9]$. A standardized in vitro tissue model for screening new drug compounds for toxicity and efficacy would be more predictive of the human liver.

Recent advances in stem cell research and tissue engineering have opened up several new avenues for the development of novel cell-based therapies and in vitro techniques for hepatology research. This paper gives an overview of the stem cell and tissue engineering approaches that have been developed or adapted by different research groups, with special emphasis on the derivation of hepatic endoderm (HE) from human embryonic stem cells (hESCs), and its clinical application in regenerative medicine.

\section{Tissue Engineering and Regenerative Medicine}

Regenerative medicine and tissue engineering are branches of medicine which focus on the creation of living, functional tissues to repair or replace damaged tissues or organs and restore their function $[10,11]$. Together, they promise enormous therapeutic opportunity and may play an important role in reducing the need for whole organ transplantation and greatly accelerate the development of new drugs and medicines [12].

\section{Liver Diseases}

FHF is the most serious of all liver diseases and is usually defined as the severe impairment of hepatic function in the absence of pre-existing liver disease. It can occur within 10 days of liver dysfunction (hyper-acute), within 10-31 days (acute) or after more than 31 days (subacute). The pathophysiology of this condition consists of the loss of hepatocellular function causing severe metabolic derangements, impairment of plasma detoxification, hyperammonemia (elevated blood ammonia levels), neurological complications, and systemic organ failure $[13,14]$. Acute-on-chronic liver disease occurs in patients with well compensated chronic liver disease in whom acute deterioration of liver function occurs due to events such as sepsis, gastrointestinal bleeding, ischemia or additional superimposed liver injury due to alcohol, hepatotoxic drugs, or viral infections. It is characterised by systemic circulatory disturbances, hepatorenal failure, and hepatic encephalopathy. Chronic hepatic decompensation occurs in patients with end stage cirrhosis and underlying liver disease [15-17].

The onset of liver failure is potentially reversible, and considerable work has been carried out to develop effective support devices capable of emulating human liver function to allow patient recovery following acute deterioration [18]. Artificial liver and bioartificial liver devices have been specifically developed to bridge patients until either a suitable organ becomes available for transplantation, or recovery occurs in the patient.

\section{Artificial Liver Devices (ALDs)}

The key factors identified in the pathophysiology of hepatic encephalopathy in liver disease are hyperammonemia caused by urea cycle enzyme deficiency, and changes in levels of GABA, benzodiazepines, 5-HT, aromatic amino acids, mercaptens, phenols, and fatty acids $[19,20]$. Artificial liver devices are designed to filter the accumulation of these toxic substances using the principles of hemofiltration, hemoperfusion, and hemodiabsorption [3]. Although ALDs have produced clinical improvements in some patients, significant increases in survival rates have not been obtained [21]. Moreover, there are side effects associated with such filtration techniques, for example, incompatibility between blood and extracorporeal circuit causing complement initiation, platelet activation, and leucopoenia (decreased white blood cell count) leading to systemic inflammatory response and hemorrhaging. Another drawback of filtration is that it removes some of the hormones and growth factors involved in liver regeneration [3]. The plasma exchange system was developed to overcome these drawbacks, allowing the removal of hepatic toxins while replacing the beneficial factors. However, this process is expensive and associated with coagulation imbalance and citrate load, limiting its clinical applicability [3].

One of the most commonly used ALDs is the molecular adsorbents recirculating system (MARS). The MARS uses albumin enriched dialysate, a charcoal filter, and an ion exchange resin to filter out albumin-bound toxic metabolites which may precipitate encephalopathy and multiorgan failure. The MARS circuit is impermeable to albumin but allows the diffusion of toxic molecules bound to albumin [22]. The MARS has been reported to produce improvements in physiological and neurological states but again does not significantly improve survival rates [21, 23]. Like other ALDs, it does not discriminate which molecules are filtered and therefore can remove key cytokines involved in liver regeneration such as IL-6 and TNF [3].

The Prometheus system is another ALD which has undergone clinical trial for the treatment of patients with acute-on-chronic liver failure. This system uses fractional plasma separation and an adsorption method with high flux hemodialysis using an albumin semipermeable membrane. It has been shown to be more effective than the MARS system at clearing albumin bound toxins, but offers no improvement in hemodynamics $[24,25]$. The complications associated with these techniques demonstrate the shortcomings of nonbiologic liver support devices. The detoxification of patients' blood using entirely artificial systems is far from an ideal support system for the failing organ. It is now being realized that a device with a biological component capable of performing all the metabolic and detoxifying functions of the liver could be a much more effective strategy [26, 27].

\section{Bioartificial Liver Devices}

The limitations of ALDs discussed above, along with the scarcity of donor livers, have led to the development of external liver support devices incorporating primary hepatocytes 
known as bioartificial livers (BALs). Ideally, a BAL should be able to simulate the function of the entire liver, though existing designs have yet to meet this requirement [28]. The use of living tissue in external liver support devices dates back to the 1950s, and a pioneering trial in which patients with cirrhosis were treated using cross-hemodialysis of the patients' blood with that of four living dogs [29]. One patient of four showed a reduction in serum ammonia levels and temporarily recovered from a hepatic coma. However, the technique was complicated, nonscalable and had little long term clinical impact. The true potential of extracorporeal liver perfusion systems was not realised until the 1990s, when human cadaveric livers that were unsuitable to be transplanted were used to successfully bridge patients with acute hepatic failure to transplantation [30].

Although early BAL studies showed great promise, there are a number of problems associated with the use of primary hepatocytes. Maintaining the long-term metabolic functions of BALs is difficult as mature hepatocytes scarcely proliferate and rapidly lose their hepatic function ex vivo [31]. Bioartificial liver support using an Academic Medical Centre (AMC) BAL bioreactor has demonstrated efficacy in phase I clinical trials, in which patients exhibited improvements in neurological status and hemodynamics [32]. In one case a patient on the transplant list fully recovered and did not require solid organ transplantation [33]. Although promising, these trials were conducted using a BAL charged with porcine hepatocytes, and concerns have been raised over the safety of using animal cells in clinical therapies due to the possibility of disease transmission. In support of this, a recent paper by Frühauf et al. [34] demonstrated that porcine hepatocyte-fuelled BALs were able to infect primary human hepatocytes with the porcine retrovirus. The risks associated with using liver support devices incorporating animal tissue have limited their clinical application, and the use of porcine hepatocytes for BAL treatment is prohibited in several European countries [35]. Other bioartificial devices such as Hepta Assist, Modular Extracorporeal Liver Support, Bioartificial Support System, and Radial Flow Bioreactor have also been used in Phase I clinical trials (reviewed in [26]). The extracorporeal liver assist device (ELAD) charged with the human cell line C3A has been shown to be of advantage in patients with FHF in terms of bridging to transplantation, although human cell lines generally display poor liver function [36]. A fully functioning humanised alternative to porcine hepatocytes could lead to a stable and reliable solution to the problem of managing and treating human liver disease. Efforts to achieve this feat have been focussed on the emerging fields of stem cell research and tissue engineering. There are three key criteria to consider in the development of stem cell derived liver technology: expandable cellular resource, efficient directed differentiation, and high fidelity function.

\section{Hepatocellular Resources}

Hepatocytes constitute about two thirds of the total cell population in the liver parenchyma and perform a variety of endocrine and exocrine functions. The remaining population of nonparenchymal cells is diverse and includes liver sinusoidal endothelial cells, kupffer cells, biliary cells, stellate cells, and intrahepatic lymphocytes [37]. Primary human hepatocytes (PHHs) are used to model various aspects of liver biology in vitro. The pharmaceutical industry takes particular interest in the expression and function of drug metabolising enzymes such as cytochrome P450 (CYP), drug metabolism, drug interactions, cytotoxicity, and genotoxicity in these models [38]. A major limitation of such in vitro studies is the shortage and variability of isolated PHHs. High quality donor livers are used for transplantation, therefore PHHs are generally sourced from smaller fragments of liver tissue resected for medical purposes such as primary liver metastasis, adenoma, angioma, fatty liver, and hydatid cysts $[39,40]$.

The liver is a remarkable organ as even after $70 \%$ resection it is capable of regeneration by compensatory hyperplasia within a few weeks. Hepatocyte proliferation and the growth of cellular mass are induced by cytokines from kupffer cells and stellate cells, and this is then followed by the proliferation of endothelial cells and cholangiocytes [41]. Despite the liver's resilience and capacity for regeneration it has proven extremely difficult to maintain or expand hepatocytes in cell culture [42]. Even with sophisticated media, human hepatocytes dedifferentiate extensively within a few hours of plating $[8,9]$, losing hepatic specific gene expression and function [42]. At present, most studies are conducted with human cell lines and rodent hepatocytes. Although a readily available replacement for $\mathrm{PHHs}$, these models suffer from poor function and species specific variation, complicating data extrapolation to humans. An example of this occurring is the case of Troglitazone, which is a member of the thiazolidinedione class of oral hypoglycaemic agents. It was approved for marketing by the Food and Drug Administration (FDA) in March 1997, but was withdrawn from the market in March 2000 after causing at least 90 cases of liver failure, 70 of which resulted in death or transplantation [43]. Current attention is focussed on finding a reliable source of human hepatocytes. The generation of hepatic endoderm from pluripotent stem cells is now being identified as one such resource to meet this demand [27]. Human embryonic stem cells are derived from the inner cell mass of preimplantation embryos and possess the ability to self-renew and differentiate to all cell types $[44,45]$. These attributes in theory give them the potential to provide an unlimited supply of replacement cells for regenerative medicine [46]. Their adult and fetal stem cell counterparts have also been suggested as potential cell sources, but these have limited capacity to multiply as compared to hESCs. Moreover, they are present in minute quantities, are difficult to isolate and purify.

\section{Directed Differentiation of hESCs to Hepatic Endoderm}

Using developmental signalling physiology, it is possible to drive hESC differentiation to functional HE [47-60]. 


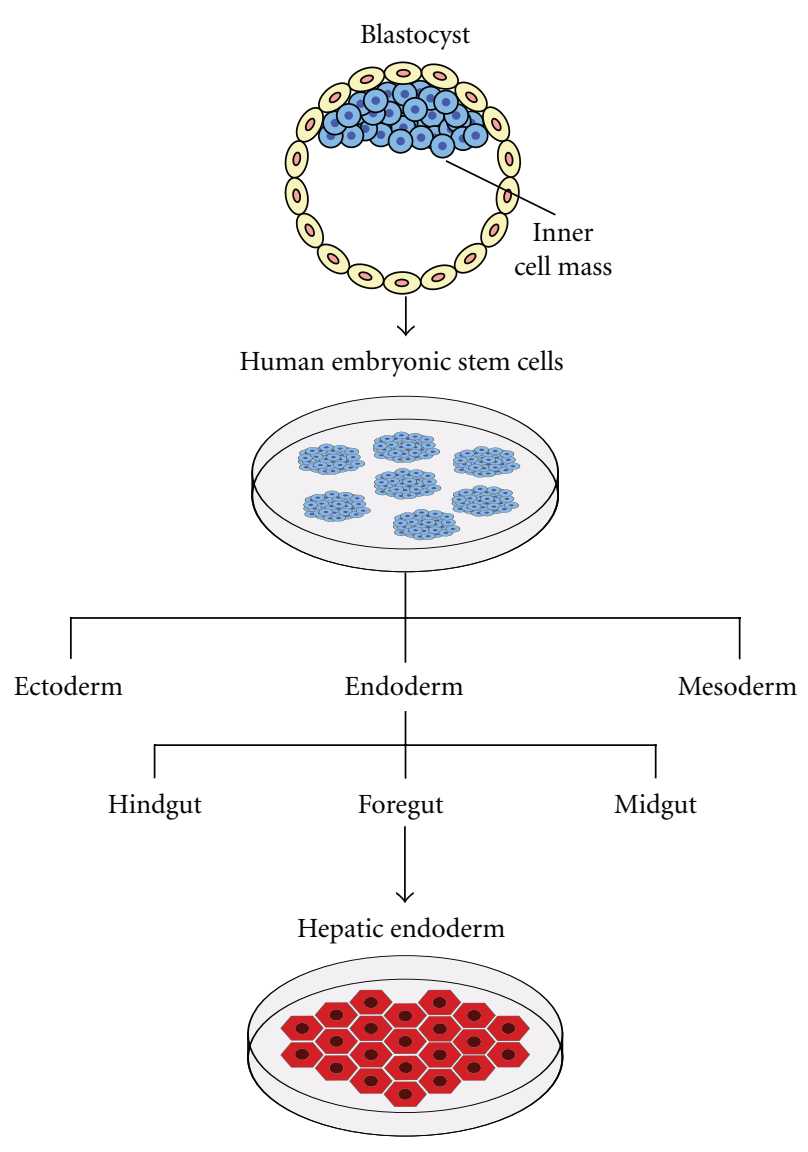

FIGURE 1: Schematic diagram of the derivation of hepatic endoderm from human embryonic stem cells.

This can be achieved either by spontaneous differentiation through the formation of embryoid bodies (EBs), or by direct differentiation (Figure 1). Spontaneous differentiation of hESCs results in the formation of EBs consisting of a mixed cell population of all three germ layers [48]. These EBs have been shown to differentiate spontaneously into HE $[47,49,50]$, but this occurs with limited efficiency. Recently, specific growth factors have been identified to direct hepatic differentiation following EB formation. However, differentiated cell populations still require purification following this process [51]. A number of studies have shown that faster, more efficient production of $\mathrm{HE}$ can be achieved through direct differentiation without the formation of EBs [52-57].

In 2007 we described the differentiation of HE from hESCs. Although the hESC derived HE was shown to exhibit hepatocyte morphology, gene expression, and function, the yield was only $10 \%$. Following on from this, we developed a more efficient differentiation protocol by priming hESC differentiation to HE [53]. Further work in our laboratory identified activin A and Wnt3a signalling as key factors in the development of functional HE, and demonstrated for the first time highly efficient and scalable derivation of functional HE derived from hESCs [54, 55].

In the future hESCs could potentially provide an inexhaustible source of hepatocytes, but their utility in both cell-based assays and the clinic depends on their functional repertoire [58-60]. Stem cells and somatic cells generally have limited function without the specialized tissue microenvironment known as the "niche." Key niche components and interactions in vivo include growth factors, cell-cell contacts, and cell-matrix adhesions which regulate tissue generation, maintenance, and repair [61,62]. Engler et al. [63] demonstrated that variations in extracellular matrix (ECM) alone are capable of affecting hESC differentiation, without any changes in serum conditions or soluble factors. The cell niche is inherently three dimensional (3D) and its biochemistry and topology strongly affect the differentiation and maturation process [64]. The main limitation of existent two-dimensional (2D) cellular assays is that they do not mimic the response of cells in the 3D milieu of tissues in vivo $[65,66]$. The use of $3 \mathrm{D}$ modelling systems may provide an insight into cellular interactions and physiology that could be translated to $2 \mathrm{D}$ models in vitro allowing the development of a scalable high fidelity resources for drug testing or BAL construction.

\section{Tissue Architecture and the Role of Extracellular Matrix}

The ECM is well defined as the dynamic modulator of various cellular processes including homeostasis, differentiation, and repair [67]. Extracellular matrices are primarily composed of four molecular groups: collagen, elastin, structural glycoproteins, and proteoglycan. The complex ECMs secreted by mammalian cells form intricate scaffolds on which cells congregate and form 3D matrices. This unique compositional and structural combination facilitates biophysical and biochemical functions such as the transport of soluble signalling molecules, nutrients, and metabolic wastes, and provides mechanical integrity by absorbing compressive and tensile stresses [68]. It is organized and sensed by cells through integrins, which are membrane spanning heterodimers modulating communication between the ECM and the cell. The hepatic ECM has been studied extensively due to its importance in hepatic homeostasis and its prominent role in cirrhosis [69]. Hepatocytes exhibit a striking polarity that is expressed at multiple levels, in overall cell shape, distribution of the cytoskeleton and organelles, and in the division of the plasma membrane into three functionally and compositionally distinct domains: basolateral, canalicular, and lateral. At the basal surface the transport of small molecules across membranes and the exchange of metabolites with blood take place, whereas the secretion of bile acids and detoxification products occurs on the apical domain [70]. The ability to modulate hepatocyte polarity and multicellular organization is important in developing in vitro systems designed to perform liver functions. Extracellular matrix isolated from liver tissue has been shown to maintain the phenotype of hepatocytes in culture [71]. It has also been shown that optimisation of the physical and chemical properties of ECM is important for the maintenance of hepatocyte function in vitro [72], and 
this is essential for developing a BAL. Chang and HughesFulford [73] demonstrated that 3D culture of the hepatocyte cell line, HepG2, in rotating wall vessel bioreactors led to the formation of spheroids with enhanced cytochrome P450 activity and albumin production. However, it should be noted that transfer of the spheroids to tissue culture dishes led to loss of function and disintegration. In another study, albumin secretion activity in fetal liver cells was shown to be one order of magnitude higher in cells cultured on 3D porous polymer scaffolds than in those grown in monolayers [74]. The limitations of existing 2D tissue culture techniques have necessitated the creation of 3D microenvironments incorporating materials, implants, and biophysical stimuli optimised for modulation of cell functions [75].

\section{Biomaterial Scaffolds: 3D Modelling}

Scaffolds provide an architectural context in which cellmatrix, cell-cell, and growth factor interactions combine to create regenerative niches [76]. Biomaterial-based scaffolds could provide a 3D environment for cells, both in culture and inside the body. Such 3D systems have been shown to enhance osteogenesis [77], hematopoiesis [78], and neural differentiation $[79,80]$, and provide greater support for hepatocyte proliferation and functionality than routine $2 \mathrm{D}$ tissue culture $[81,82]$. Recent research has focused on the development of biomaterials designed to mimic the unique characteristics of natural ECM. Ideal biomaterials should be strong enough to bear the physiological load, be resistant to undesired degradation or corrosion, noncarcinogenic, nonimmunogenic, antileukotactic, and nonmutagenic. Biocompatibility is another important feature of biomaterials and this depends on their material composition, surface wettability, roughness, charge, size, and shape. The nature of the biomaterial surface including its hydrophobicity and hydrophilicity determines how proteins interact with the surface upon adsorption [83]. The biomaterials in use for tissue engineering can be broadly classified as biodegradable and nonbiodegradable. The nonbiodegradable biomaterials consist of metals, ceramics, and composites, which have been used as integral components in bone and dental replacements $[84,85]$. The biodegradable biomaterials, both natural and synthetic, closely resemble the consistency of native tissue and make attractive scaffold materials for soft tissue engineering. Polymers, both natural and synthetic, are of special interest for liver engineering. They are organic in nature and the most diverse of the biomaterials, varying mechanically and physically, and possessing different chemical reactivities and degradation properties. Polymers offer greater flexibility in design, composition, and structure, and can be tailored for specific needs.

The derivatives of natural ECM are used as biomaterials for scaffolds in liver studies as it has been recognized that in vivo cues such as ECM, cell signaling, and soluble factors could hold the key to producing fully mature and functional hepatocytes. Collagen is one such natural ECM component found in bone, skin, ligaments, and connective tissues. It provides a substrate for cellular recognition, cell attachment, proliferation, and differentiation. Imamura et al. [50] showed that hESCs cultured as EBs in a polypropylene conical tube inserted into a collagen scaffold $3 \mathrm{D}$ culture system supplemented with exogenous growth factors and hormones were able to produce HE displaying liver gene expression and albumin production. Similar success with 3D collagen culture systems was published by Baharvand et al. [49]. Hyaluronic acid is another ECM component found in embryonic and fetal tissues. It is involved in cell expansion and proliferation and plays a prime role in cell behaviour and cell signalling in vivo. Human hepatoblasts and hepatic stem cells express hyaluronan receptors (CD44). Hyaluronans are glycosaminoglycans and form highly reactive biomaterials. Turner et al. [86] demonstrated the formation of cell aggregates by hepatoblasts and hepatic stem cells in hyaluronan hydrogels, which maintained viability and phenotype for 4 weeks. However, the major drawbacks of natural ECM components are their variable chemical and physical properties and the ethical and safety issues associated with their derivation. Therefore, plant, animal, and insect components have been explored to develop natural biomaterials such as silk, chitosan, alginate, and matrigel. Silk fibroin is derived from silk worm cocoons and has FDA approval for use in surgery and drug delivery. The porous silk scaffolds are developed using gas foaming or salt leaching techniques. Silk fibroin microfluid devices have been shown to support proliferation and the development of liver specific functions in HepG2 cells [87]. Chitosan is a natural biopolymer consisting of glucosamine and $\mathrm{N}$-acetylglucosamine obtained by deacetylation of chitin. Chitosan albumin matrix has been demonstrated to support fetal porcine attachment for creating liver tissue organoids [88]. Natural hydrogels such as matrigel and alginate have been extensively used by several groups for 3D culture of hepatocytes due to their biocompatibility, mild gelling conditions, and improved cell entrapment properties. Matrigel is composed of solubilized basement membrane proteins extracted from mouse chondrosarcomas and consists of laminin, collagen IV, and heparin sulphate proteoglycan [84]. Hepatocytes cultured on matrigel have been shown to cluster into multicellular spheroids, but appear less polygonal than hepatocytes in vivo $[89,90]$. Although matrigel is an excellent biomaterial because of its abundance of natural biological molecules, its heterogeneous nature and unidentified molecular components reduce a degree of experimental control. Additionally, its xeno origin and derivation from chondrosarcoma limit its potential for cell therapies and tissue engineering as per good manufacturing practice (GMP) standards. Alginate is extracted from seaweed and thus is readily available. It is composed of 2 monomers (a-L guluronic acid and b-D mannuronic acid) and is an attractive biomaterial because of its gelation property which can occur through the addition of ionic cross linkers or divalent cations such as $\mathrm{Ca}^{2+}, \mathrm{Ba}^{2+}$, and $\mathrm{Sr}^{2+}$ [91]. Alginate has been used as a delivery system for drugs, an extracellular material for basic biological studies, and as a scaffold for tissue engineering [92]. Human EBs cultured in alginate micro beads supplemented with exogenous growth factors 
have been shown to differentiate into HE expressing alphafetoprotein (AFP), albumin, CYP7A1, and cytokeratin 18 [93]. Cheng et al. showed that alginate gel encapsulation also supports the growth and differentiation of hepatic progenitor cells derived from human fetal livers [81]. Hepatocyte functions such as ammonia detoxification, albumin secretion, P450 expression, and the development of bile ducts were also reported in this study. In another study, cultivation of the C3A human hepatocyte cell line within alginate scaffolds led to the formation of spheroids with improved drug metabolism and phase II activity compared to 2D monolayer cultures [82].

The use of natural polymers in 3D systems mimics in vivo histoarchitecture and provides easy manipulation of cells and tissues as well as promoting cell-matrix interactions. These provide a microenvironment conducive to normal progenitor cell kinetics and enhance cell differentiation. The major disadvantages of using natural materials are the limited control over physiochemical properties that they offer, as well as immunogenicity, degradability, lack of reproducibility, and inconsistency in mechanical properties.

\section{Synthetic Polymers}

Synthetic biopolymers offer an advantage over natural materials as they can be tailored to possess a wide range of properties, are GMP scalable, and can be made biocompatible. Biodegradable polymer scaffolds provide frameworks for tissue regeneration and cell transplantation and can be made to degrade over time [94]. At present, the most common biodegradable polymers in use or being studied include polylactic acid (PLA), poly-L-lactic acid (PLLA), polyglycolic acid (PGA), polyanhydrides, polyfumarates (PF), polyorthoesters, polycaprolactones (PCL), and polycarbonates $[95,96]$.

Poly ( $\alpha$-hydroxy acids) consist of PGA and PLLA homopolymers and their copolymers (PLGA), as well as polylactic acid stereo copolymers produced using L-, D-, or DL-lactides and racemic polymer copolymer PLDLA [97]. They are used in surgical sutures and implant devices [98] and hence have been used by several research groups as the material of choice for liver tissue engineering. Huang et al. showed that PLLA polymer-based 3D culture with appropriate biofactors promoted the functional maturation of fetal porcine hepatocytes [99]. Jiang et al. [100] had similar success, using a PLLA scaffold to culture mouse fetal liver cells which produced albumin at levels comparable to adult mouse hepatocytes. In vitro growth and maturation of rat fetal liver cells on PLLA macroporous scaffolds has also been reported. These cells maintained a high level of hepatic function including albumin secretion and cytochrome P450 activity for 2 weeks, whilst monolayer function decreased after 7 days in culture [101]. Furthermore, Cho et al. [102] reported efficient infection of hepatitis $\mathrm{C}$ virus and obtained progeny of infective virus in the supernatant of $3 \mathrm{D}$ PEG hydrogel encapsulated cells.

The limitations of poly ( $\alpha$ hydroxy acids) include bulk degradation, surface erosion, and hydrophobicity [103].
Degradation occurs by hydrolysis, accounting for the accumulation of acid by-products which can lead to inflammatory responses in vivo, specifically in areas of poor vascularisation. These drawbacks could be reduced by scaffold chemistry patterning using protein stamping, photochemical modification, and the incorporation of specific bioactive domains onto the scaffold surface for cell adhesion, migration, tissue ingrowth, and repair $[104,105]$.

Another group of synthetic polymers attracting attention for hepatocyte 3D culture is polyurethanes. These are one of the most broadly used polymers in implantable biomedical devices such as artificial hearts, cardiac pacemakers and structural tissue replacements [106]. Ijima et al. demonstrated the formation of spherical multicellular aggregates of adult rat hepatocytes in pores of polyurethane foam (PUF) $[107,108]$. The culture of porcine hepatocyte spheroids using PUF has also been reported and translated to the clinic as a hybrid artificial liver device [109]. More recently Matsumoto et al. [110] demonstrated that mouse embryonic stem cells formed spheroids on PUF foam, and that the addition of specific growth factors initiated hepatic differentiation and expression of HE markers such as AFP, albumin, and tryptophan 2, 3-dioxygenase.

\section{Design: Tailor Made Polymers for Tissue Engineering}

The advantage of using synthetic polymers is the wide choice they offer in design parameters including porosity, pore connectivity, pore geometry, pore size distribution, and surface topography. Such polymers can be designed to aid efficient diffusion of nutrients, metabolic wastes and soluble molecules, and the facilitation of mass transport within 3D matrices to control the efficiency of cell seeding [111]. They can be tailored to achieve appropriate designs for specific cell groups using different approaches such as spin casting, leaching, emulsion freeze drying, rapid prototyping, and stereolithography [112].

It is increasingly being recognised that cells respond to the physical characteristics of the substrate on which they are grown [113]; therefore it is important to tune features such as void and interconnect size, surface area and mechanical properties for constructing biomaterial scaffolds. The two morphological designs that have become more popular among tissue engineers are fibrous matrices and sponge-like matrices. Fibrous matrices have a high surface area-to-volume ratio and a structure similar to the 3D fibre network of collagen and elastin found in natural ECM. The major disadvantage of fibrous structures is the presence of small pores among the fibres which considerably hamper cell migration. Sponge-like matrices have an advantage in their design and structure with porosity and interconnectivity that can be regulated. The HepG2 cell line cultured on spongelike polystyrene scaffolds has been shown to retain higher levels of cell viability, cellular morphology, and hepatocyte functionality compared to their counterparts cultured on standard 2D plastic [114]. 


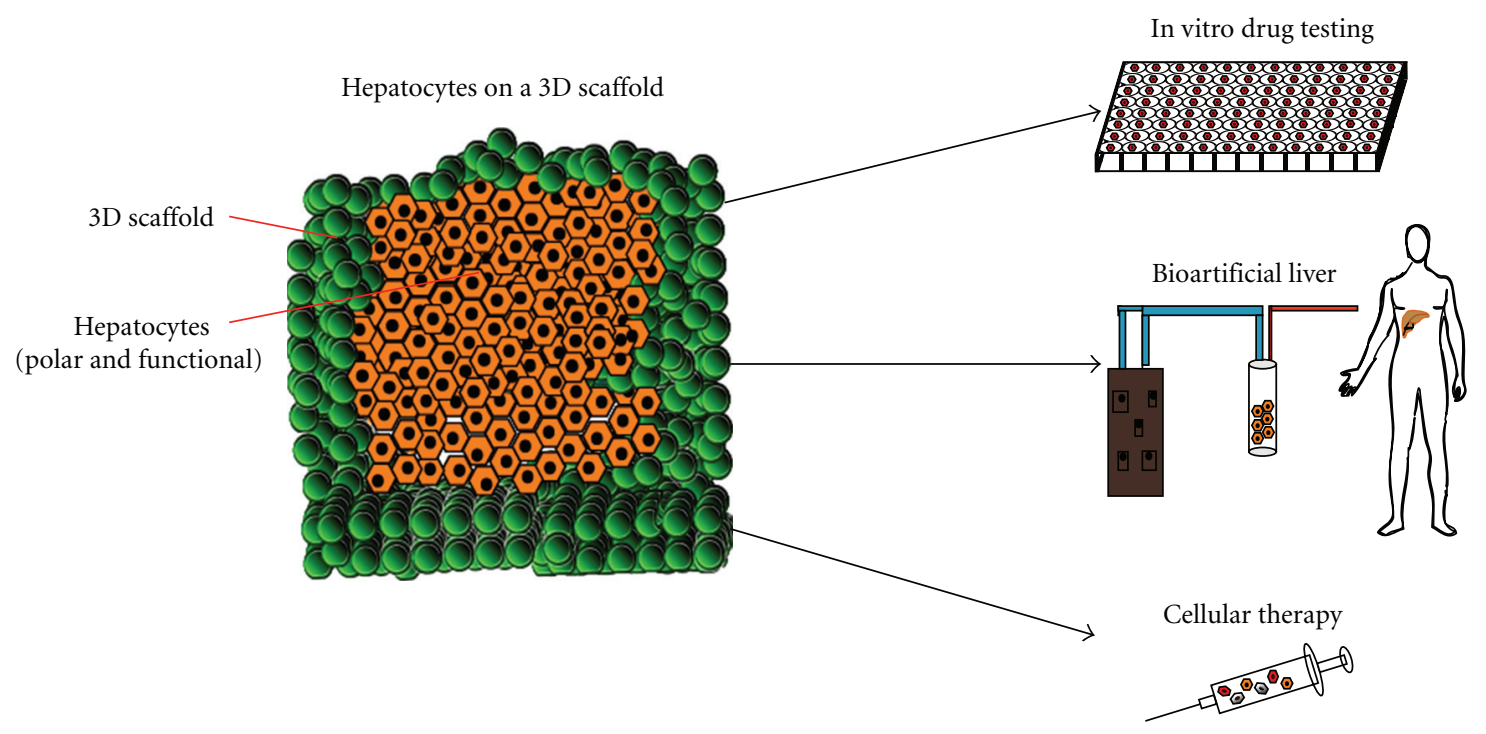

FIgURE 2: Schematic diagram of 3D culture of hepatocytes on a polymer scaffold, and the potential applications of this technology.

Analysing the behaviour of cells on scaffolds is important to ensure cell viability and function in tissue engineered constructs [115]. However, the optimal distribution and migration of seeded cells throughout the scaffold remains an issue. The most common cell seeding techniques are static seeding and dynamic seeding. Static seeding consists of surface seeding and direct injection whereas dynamic seeding involves the movement of cell solution through and around the scaffold to achieve a more homogeneous distribution [116]. Another popular technique is cell entrapment, which has been extensively used in constructing 3D in vitro model systems. Cell entrapment techniques are based on the selfassembly of materials around cells, rather than the shaping of a bulk material to specific architecture [117].

In vivo cellular interaction with ECM proteins is very complex as these proteins present cells with multiple cell binding and growth factor binding domains. To simulate in vivo cellular interactions in vitro, the biomaterials can be coated with specific amino acid subunits to attain more defined conditions. The peptide sequence RGDS (arggly-asp-ser) from vitronectin and fibronectin has been recognized as a minimal sequence required for integrin mediated cell adhesion [118]. Another such defined sequence is IKVAV (ile-lys-val-ala-val) found in laminin [119]. Human mesenchymal stem cells have been shown to change from a fibroblast shape in a $2 \mathrm{D}$ culture system to a compact shape on an RGD (arg-gly-asp) alginate culture system [120]. Furthermore, Hybrid RGD/galactose substratum has also been shown to support hepatocyte functions [121].

Novel biomaterials are being designed to be able to respond to biological environmental stimulation. Such "smart materials" respond to specific cellular signals and include hydrogels containing matrix metalloproteinase degradable sites [122]. These allow native cells to control gel remodelling such that cells replace the synthetic gel material with tissue upon in vivo transplantation. These materials could be made biocompatible and thereby avoid nonspecific protein adsorption. Therefore, efforts are focused on developing 3D matrices containing self-assembling peptides that could direct cellular differentiation to a specific lineage [123]. Semino et al. [124] used self-assembling peptide scaffolds to culture the rat hepatocyte progenitor cell line, lig8. The resulting cell population derived in a 3D manner showed expression of definitive endoderm markers such as HNF3 $\beta$, cytokeratin 8 , and AFP. The expression of mature hepatocyte markers however was not evident, despite observation of other mature hepatocyte properties. Magnetic nanoparticles and quantum dots have also been suggested for stem cell labelling and in vivo tracking, and such engineered nanometer-scale scaffolds could be used for stem cell differentiation and transplantation [125].

The major limitation of tissue engineering methodologies is poor simulation of the complex architecture and abundant vasculature of the liver. In vivo, cells at a distance of more than $0.1 \mathrm{~mm}$ from vascularity cannot survive and cells within bioengineered tissue have similarly stringent requirements, as diffusion within scaffolds is limited to a few hundred micrometers [126]. Poyck et al. [127] have shown in an AMC bioartificial liver model that long-term culture of primary porcine hepatocytes is improved by increased anaerobic glycolysis, which leads to better liver specific function and metabolic stability. For this reason, in high density liver cultures adequate delivery of oxygen to cells is crucial. Synthetic oxygen carriers such as perflurocarbons and cross-linked hemoglobin have been added onto scaffolds to facilitate oxygenation [128]. The latest approach has been the use of oxygen generating biomaterials, and it was reported that PLGA scaffolds containing calcium peroxidebased particles maintained elevated levels of oxygen and extended cell viability under hypoxic conditions [129]. Microfabrication and computational fluid dynamics have also been used to generate scaffold designs suitable for 
microvasculature and organ specific constructs [130-132]. Carraro et al. [133] demonstrated a microfluidics-based bilayer device with discrete parenchymal chambers designed using computational modelling. This device was able to sustain human hepatoma cells, and primary rat hepatocytes. By solving the problem of supplying cells grown in 3D tissue culture with oxygen, it will be possible to sustain the culture of hepatocytes in vitro for extended periods, facilitating cell studies and eventually leading to the improved functionality of BALs (Figure 2).

\section{Conclusion}

The future challenge in liver research is the development of functional, reliable, xenofree $\mathrm{HE}$ that will bypass the issues associated with PHHs. The derivation of HE from hESCs could provide an unlimited source of cells for BAL construction. The three-dimensional culture of these cells with appropriate extracellular matrix and polymerbased biomaterials could provide an alternative to porcine hepatocytes leading to the generation of a humanised BAL device. More recently the generation of induced pluripotent stems cells (iPSCs), by transfection of key pluripotency genes into somatic cells, has led to a new era in regenerative medicine. These cells are free from the ethical complications associated with hESCs and can be tailor-made for patients. $\mathrm{HE}$ derived from iPSCs and its incorporation into a BAL device may therefore play an important role in the treatment of human liver disease and the prediction of drug toxicity.

\section{Acknowledgments}

Dr. D. Hay was supported by an RCUK fellowship. Dr. R. Sharma, Mr. S. Greenhough, and Dr. C. Medine were supported by the UK Stem Cell Foundation and Scottish Enterprise. R. Sharma and S. Greenhough contributed equally to this work.

\section{References}

[1] G. Ramadori, F. Moriconi, I. Malik, and J. Dudas, "Physiology and pathophysiology of liver inflammation, damage and repair," Journal of Physiology and Pharmacology, vol. 59, supplement 1, pp. 107-117, 2008.

[2] T. E. Starzl and F. G. Lakkis, "The unfinished legacy of liver transplantation: emphasis on immunology," Hepatology, vol. 43, no. 2, supplement 1, pp. S151-S163, 2006.

[3] F. G. Court, S. A. Wemyss-Holden, A. R. Dennison, and G. J. Maddern, "Bioartificial liver support devices: historical perspectives," ANZ Journal of Surgery, vol. 73, no. 9, pp. 739748, 2003.

[4] S. Raia, J. R. Nery, and S. Mies, "Liver transplantation from live donors," The Lancet, vol. 2, no. 8661, p. 497, 1989.

[5] D. S. Seaman, "Adult living donor liver transplantation: current status," Journal of Clinical Gastroenterology, vol. 33, no. 2, pp. 97-106, 2001.

[6] R. A. F. M. Chamuleau, T. Deurholt, and R. Hoekstra, "Which are the right cells to be used in a bioartificial liver?" Metabolic Brain Disease, vol. 20, no. 4, pp. 327-335, 2005.
[7] R. K. Verbeeck, "Pharmacokinetics and dosage adjustment in patients with hepatic dysfunction," European Journal of Clinical Pharmacology, vol. 64, no. 12, pp. 1147-1161, 2008.

[8] E. F. A. Brandon, C. D. Raap, I. Meijerman, J. H. Beijnen, and J. H. M. Schellens, "An update on in vitro test methods in human hepatic drug biotransformation research: pros and cons," Toxicology and Applied Pharmacology, vol. 189, no. 3, pp. 233-246, 2003.

[9] R. Gebhardt, J. G. Hengstler, D. Müller, et al., "New hepatocyte in vitro systems for drug metabolismml: metabolic capacity and recommendations for application in basic research and drug development, standard operation procedures," Drug Metabolism Reviews, vol. 35, no. 2-3, pp. 145213, 2003.

[10] D.-H. Park, C. V. Borlongan, D. J. Eve, and P. R. Sanberg, "The emerging field of cell and tissue engineering," Medical Science Monitor, vol. 14, no. 11, pp. RA206-RA220, 2008.

[11] G. F. Muschler, C. Nakamoto, and L. G. Griffith, "Engineering principles of clinical cell-based tissue engineering," Journal of Bone and Joint Surgery. American, vol. 86, no. 7, pp. 1541-1558, 2004.

[12] C. Mason and P. Dunnill, "The strong financial case for regenerative medicine and the regen industry," Regenerative Medicine, vol. 3, no. 3, pp. 351-363, 2008.

[13] D. Gotthardt, C. Riediger, K. H. Weiss, et al., "Fulminant hepatic failure: etiology and indications for liver transplantation," Nephrology, Dialysis, Transplantation, vol. 22, supplement 8, pp. viii5-viii8, 2007.

[14] S. A. Khan, N. Shah, R. Williams, and R. Jalan, "Acute liver failure: a review," Clinics in Liver Disease, vol. 10, no. 2, pp. 239-258, 2006.

[15] S. Sen, R. Williams, and R. Jalan, "The pathophysiological basis of acute-on-chronic liver failure," Liver, vol. 22, supplement 2, pp. 5-13, 2002.

[16] R. Jalan and R. Williams, "Acute-on-chronic liver failure: pathophysiological basis of therapeutic options," Blood Purification, vol. 20, no. 3, pp. 252-261, 2002.

[17] R. Jalan, "Acute liver failure: current management and future prospects," Journal of Hepatology, vol. 42, supplement 1, pp. S115-S123, 2005.

[18] R. Jalan and R. Williams, "Bio-artificial liver support for acute liver failure: should we be using it to treat patients?" Transplantation, vol. 73, no. 2, pp. 165-166, 2002.

[19] R. Jalan and J. Bernuau, "Induction of cerebral hyperemia by ammonia plus endotoxin: does hyperammonemia unlock the blood-brain barrier?" Journal of Hepatology, vol. 47, no. 2, pp. 168-171, 2007.

[20] C. H. C. Dejong, M. C. G. van de Poll, P. B. Soeters, R. Jalan, and S. W. M. Olde Damink, "Aromatic amino acid metabolism during liver failure," Journal of Nutrition, vol. 137, no. 6, pp. 1579S-1585S, 2007.

[21] J. P. Liu, L. L. Gluud, B. Als-Nielsen, and C. Gluud, "Artificial and bioartificial support systems for liver failure," Cochrane Database of Systematic Reviews, no. 1, Article ID CD003628, 2004.

[22] L. L. Kjaergard, J. Liu, B. Als-Nielsen, and C. Gluud, "Artificial and bioartificial support systems for acute and acute-on-chronic liver failure: a systematic review," Journal of the American Medical Association, vol. 289, no. 2, pp. 217222, 2003.

[23] R. Jalan, S. Sen, C. Steiner, D. Kapoor, A. Alisa, and R. Williams, "Extracorporeal liver support with molecular adsorbents recirculating system in patients with severe acute 
alcoholic hepatitis," Journal of Hepatology, vol. 38, no. 1, pp. 24-31, 2003.

[24] W. Laleman, A. Wilmer, P. Evenepoel, et al., "Effect of the molecular adsorbent recirculating system and Prometheus devices on systemic haemodynamics and vasoactive agents in patients with acute-on-chronic alcoholic liver failure," Critical Care, vol. 10, no. 4, article R108, 2006.

[25] V. Stadlbauer, P. Krisper, R. Aigner, et al., "Effect of extracorporeal liver support by MARS and Prometheus on serum cytokines in acute-on-chronic liver failure," Critical Care, vol. 10, article R169, 2006.

[26] A. Sgroi, V. Serre-Beinier, P. Morel, and L. Bühler, "What clinical alternatives to whole liver transplantation? Current status of artificial devices and hepatocyte transplantation," Transplantation, vol. 87, no. 4, pp. 457-466, 2009.

[27] N. Kobayashi, "Life support of artificial liver: development of a bioartificial liver to treat liver failure," Journal of HepatoBiliary-Pancreatic Surgery, vol. 16, no. 2, pp. 113-117, 2009.

[28] M. P. van de Kerkhove, R. Hoekstra, R. A. F. M. Chamuleau, and T. M. van Gulik, "Clinical application of bioartificial liver support systems," Annals of Surgery, vol. 240, no. 2, pp. 216 230, 2004.

[29] K. Naruse, “Artificial liver support: future aspects," Journal of Artificial Organs, vol. 8, no. 2, pp. 71-76, 2005.

[30] I. J. Fox, A. N. Langnas, L. W. Fristoe, et al., "Successful application of extracorporeal liver perfusion: a technology whose time has come," American Journal of Gastroenterology, vol. 88, no. 11, pp. 1876-1881, 1993.

[31] A. Xiong, T. W. Austin, E. Lagasse, et al., "Isolation of human fetal liver progenitors and their enhanced proliferation by three-dimensional coculture with endothelial cells," Tissue Engineering Part A, vol. 14, no. 6, pp. 995-1006, 2008.

[32] C.-B. Yu, X.-P. Pan, and L.-J. Li, "Progress in bioreactors of bioartificial livers," Hepatobiliary and Pancreatic Diseases International, vol. 8, no. 2, pp. 134-140, 2009.

[33] M. P. van de Kerkhove, P. P. C. Poyck, T. Deurholt, R. Hoekstra, R. A. F. M. Chamuleau, and T. M. van Gulik, "Liver support therapy: an overview of the AMC-bioartificial liver research," Digestive Surgery, vol. 22, no. 4, pp. 254-264, 2005.

[34] J.-H. Frühauf, H. Mertsching, S. Giri, N. R. Frühauf, and A. Bader, "Porcine endogenous retrovirus released bya bioartificial liver infects primary human cells," Liver International, vol. 29, no. 10, pp. 1553-1561, 2009.

[35] R. A. F. M. Chamuleau, P. P. C. Poyck, and M.-P. van de Kerkhove, "Bioartificial liver: its pros and cons," Therapeutic Apheresis and Dialysis, vol. 10, no. 2, pp. 168-174, 2006.

[36] A. J. Ellis, R. D. Hughes, J. A. Wendon, et al., "Pilot-controlled trial of the extracorporeal liver assist device in acute liver failure," Hepatology, vol. 24, no. 6, pp. 1446-1451, 1996.

[37] V. Racanelli and B. Rehermann, "The liver as an immunological organ," Hepatology, vol. 43, no. 2, supplement 1, pp. S54-S62, 2006.

[38] D. M. Cross and M. K. Bayliss, "A commentary on the use of hepatocytes in drug metabolism studies during drug discovery and development," Drug Metabolism Reviews, vol. 32, no. 2, pp. 219-240, 2000.

[39] N. Cheng, E. Wauthier, and L. M. Reid, "Mature human hepatocytes from ex vivo differentiation of alginate-encapsulated hepatoblasts," Tissue Engineering Part A, vol. 14, no. 1, pp. 17, 2008.

[40] I. J. Fox and S. C. Strom, "To be or not to be: generation of hepatocytes from cells outside the liver," Gastroenterology, vol. 134, no. 3, pp. 878-881, 2008.
[41] P. A. Clavien and R. Graf, "Liver regeneration and platelets," British Journal of Surgery, vol. 96, no. 9, pp. 965-966, 2009.

[42] J. P. Miranda, S. B. Leite, U. Muller-Vieira, A. Rodrigues, M. J. T. Carrondo, and P. M. Alves, "Towards an extended functional hepatocyte in vitro culture," Tissue Engineering Part C, vol. 15, no. 2, pp. 157-167, 2009.

[43] E. A. M. Gale, "Lessons from the glitazones: a story of drug development," The Lancet, vol. 357, no. 9271, pp. 1870-1875, 2001.

[44] J. A. Thomson, J. Itskovitz-Eldor, S. S. Shapiro, et al., "Embryonic stem cell lines derived from human blastocysts," Science, vol. 282, no. 5391, pp. 1145-1147, 1998.

[45] B. E. Reubinoff, M. F. Pera, C.-Y. Fong, A. Trounson, and A. Bongso, "Embryonic stem cell lines from human blastocysts: somatic differentiation in vitro," Nature Biotechnology, vol. 18, no. 4, pp. 399-404, 2000.

[46] H. J. Rippon and A. E. Bishop, "Embryonic stem cells," Cell Proliferation, vol. 37, no. 1, pp. 23-34, 2004.

[47] N. Lavon and N. Benvenisty, "Study of hepatocyte differentiation using embryonic stem cells," Journal of Cellular Biochemistry, vol. 96, no. 6, pp. 1193-1202, 2005.

[48] J. Itskovitz-Eldor, M. Schuldiner, D. Karsenti, et al., "Differentiation of human embryonic stem cells into embryoid bodies compromising the three embryonic germ layers," Molecular Medicine, vol. 6, no. 2, pp. 88-95, 2000.

[49] H. Baharvand, S. M. Hashemi, S. K. Ashtiani, and A. Farrokhi, "Differentiation of human embryonic stem cells into hepatocytes in 2D and 3D culture systems in vitro," International Journal of Developmental Biology, vol. 50, no. 7, pp. 645-652, 2006.

[50] T. Imamura, L. Cui, R. Teng, et al., "Embryonic stem cell-derived embryoid bodies in three-dimensional culture system form hepatocyte-like cells in vitro and in vivo," Tissue Engineering, vol. 10, no. 11-12, pp. 1716-1724, 2004.

[51] H. Basma, A. Soto-Gutiérrez, G. R. Yannam, et al., "Differentiation and transplantation of human embryonic stem cellderived hepatocytes," Gastroenterology, vol. 136, no. 3, pp. 990-999, 2009.

[52] D. C. Hay, D. Zhao, A. Ross, R. Mandalam, J. Lebkowski, and W. Cui, "Direct differentiation of human embryonic stem cells to hepatocyte-like cells exhibiting functional activities," Cloning and Stem Cells, vol. 9, no. 1, pp. 51-62, 2007.

[53] D. C. Hay, D. Zhao, J. Fletcher, et al., "Efficient differentiation of hepatocytes from human embryonic stem cells exhibiting markers recapitulating liver development in vivo," Stem Cells, vol. 26, no. 4, pp. 894-902, 2008.

[54] D. C. Hay, J. Fletcher, C. Payne, et al., "Highly efficient differentiation of hESCs to functional hepatic endoderm requires ActivinA and Wnt3a signaling," Proceedings of the National Academy of Sciences of the United States of America, vol. 105, no. 34, pp. 12301-12306, 2008.

[55] J. Fletcher, W. Cui, K. Samuel, et al., "The inhibitory role of stromal cell mesenchyme on human embryonic stem cell hepatocyte differentiation is overcome by Wnt3a treatment," Cloning and Stem Cells, vol. 10, no. 3, pp. 331-339, 2008.

[56] S. Agarwal, K. L. Holton, and R. Lanza, "Efficient differentiation of functional hepatocytes from human embryonic stem cells," Stem Cells, vol. 26, no. 5, pp. 1117-1127, 2008.

[57] Y. Duan, A. Catana, Y. Meng, et al., "Differentiation and enrichment of hepatocyte-like cells from human embryonic stem cells in vitro and in vivo," Stem Cells, vol. 25, no. 12, pp. 3058-3068, 2007.

[58] D. M. Dalgetty, C. N. Medine, J. P. Iredale, and D. C. Hay, "Progress and future challenges in stem cell-derived liver 
technologies," American Journal of Physiology, vol. 297, no. 2, pp. G241-G248, 2009.

[59] N. Lavon, O. Yanuka, and N. Benvenisty, "Differentiation and isolation of hepatic-like cells from human embryonic stem cells," Differentiation, vol. 72, no. 5, pp. 230-238, 2004.

[60] L. Rambhatla, C.-P. Chiu, P. Kundu, Y. Peng, and M. K. Carpenter, "Generation of hepatocyte-like cells from human embryonic stem cells," Cell Transplantation, vol. 12, no. 1, pp. $1-11,2003$.

[61] D. T. Scadden, "The stem-cell niche as an entity of action," Nature, vol. 441, no. 7097, pp. 1075-1079, 2006.

[62] D. E. Discher, D. J. Mooney, and P. W. Zandstra, "Growth factors, matrices, and forces combine and control stem cells," Science, vol. 324, no. 5935, pp. 1673-1677, 2009.

[63] A. J. Engler, S. Sen, H. L. Sweeney, and D. E. Discher, "Matrix elasticity directs stem cell lineage specification," Cell, vol. 126, no. 4, pp. 677-689, 2006.

[64] J. Lee, M. J. Cuddihy, and N. A. Kotov, "Three-dimensional cell culture matrices: state of the art," Tissue Engineering Part $B$, vol. 14, no. 1, pp. 61-86, 2008.

[65] A. Abbott, "Biology's new dimension," Nature, vol. 424, no. 6951, pp. 870-872, 2003.

[66] T. Sun, S. Jackson, J. W. Haycock, and S. MacNeil, "Culture of skin cells in $3 \mathrm{D}$ rather than $2 \mathrm{D}$ improves their ability to survive exposure to cytotoxic agents," Journal of Biotechnology, vol. 122, no. 3, pp. 372-381, 2006.

[67] P. S. Amenta and D. Harrison, "Expression and potential role of the extracellular matrix in hepatic ontogenesis: a review," Microscopy Research and Technique, vol. 39, no. 4, pp. 372386, 1997.

[68] J. A. Burdick and G. Vunjak-Novakovic, "Engineered microenvironments for controlled stem cell differentiation," Tissue Engineering Part A, vol. 15, no. 2, pp. 205-219, 2009.

[69] R. McClelland, E. Wauthier, J. Uronis, and L. Reid, "Gradients in the liver's extracellular matrix chemistry from periportal to pericentral zones: influence on human hepatic progenitors," Tissue Engineering Part A, vol. 14, no. 1, pp. 5970, 2008.

[70] S. F. Abu-Absi, J. R. Friend, L. K. Hansen, and W.-S. Hu, "Structural polarity and functional bile canaliculi in rat hepatocyte spheroids," Experimental Cell Research, vol. 274, no. 1, pp. 56-67, 2002.

[71] M. Ohno, K. Motojima, T. Okano, and A. Taniguchi, "Maturation of the extracellular matrix and cell adhesion molecules in layered co-cultures of HepG2 and endothelial cells," Journal of Biochemistry, vol. 145, no. 5, pp. 591-597, 2009.

[72] S. Ng, Y.-N. Wu, Y. Zhou, et al., "Optimization of 3-D hepatocyte culture by controlling the physical and chemical properties of the extra-cellular matrices," Biomaterials, vol. 26, no. 16, pp. 3153-3163, 2005.

[73] T. T. Chang and M. Hughes-Fulford, "Monolayer and spheroid culture of human liver hepatocellular carcinoma cell line cells demonstrate distinct global gene expression patterns and functional phenotypes," Tissue Engineering Part A, vol. 15, no. 3, pp. 559-567, 2009.

[74] T. Koyama, T. Ehashi, N. Ohshima, and H. Miyoshi, "Efficient proliferation and maturation of fetal liver cells in three-dimensional culture by stimulation of oncostatin $\mathrm{m}$, epidermal growth factor, and dimethyl sulfoxide," Tissue Engineering Part A, vol. 15, no. 5, pp. 1099-1107, 2009.

[75] L. G. Griffith and G. Naughton, "Tissue engineeringcurrent challenges and expanding opportunities," Science, vol. 295, no. 5557, pp. 1009-1010, 2002.
[76] M. Sokolsky-Papkov, K. Agashi, A. Olaye, K. Shakesheff, and A. J. Domb, "Polymer carriers for drug delivery in tissue engineering," Advanced Drug Delivery Reviews, vol. 59, no. 4-5, pp. 187-206, 2007.

[77] D. Du, K. S. Furukawa, and T. Ushida, "3D culture of osteoblast-like cells by unidirectional or oscillatory flow for bone tissue engineering," Biotechnology and Bioengineering, vol. 102, no. 6, pp. 1670-1678, 2009.

[78] H. Liu and K. Roy, "Biomimetic three-dimensional cultures significantly increase hematopoietic differentiation efficacy of embryonic stem cells," Tissue Engineering, vol. 11, no. 12, pp. 319-330, 2005.

[79] D. R. Nisbet, D. Moses, T. R. Gengenbach, J. S. Forsythe, D. I. Finkelstein, and M. K. Horne, "Enhancing neurite outgrowth from primary neurones and neural stem cells using thermoresponsive hydrogel scaffolds for the repair of spinal cord injury," Journal of Biomedical Materials Research Part A, vol. 89, no. 1, pp. 24-35, 2009.

[80] E. Syková, P. Jendelová, L. Urdzíková, P. Lesný, and A. Hejčl, "Bone marrow stem cells and polymer hydrogelstwo strategies for spinal cord injury repair," Cellular and Molecular Neurobiology, vol. 26, no. 7-8, pp. 1113-1129, 2006.

[81] N. Cheng, E. Wauthier, and L. M. Reid, "Mature human hepatocytes from ex vivo differentiation of alginate-encapsulated hepatoblasts," Tissue Engineering Part A, vol. 14, no. 1, pp. 17, 2008.

[82] T. Elkayam, S. Amitay-Shaprut, M. Dvir-Ginzberg, T. Harel, and S. Cohen, "Enhancing the drug metabolism activities of C3A-a human hepatocyte cell line-by tissue engineering within alginate scaffolds," Tissue Engineering, vol. 12, no. 5, pp. 1357-1368, 2006.

[83] P. Roach, D. Eglin, K. Rohde, and C. C. Perry, "Modern biomaterials: a review-bulk properties and implications of surface modifications," Journal of Materials Science: Materials in Medicine, vol. 18, no. 7, pp. 1263-1277, 2007.

[84] E. Dawson, G. Mapili, K. Erickson, S. Taqvi, and K. Roy, "Biomaterials for stem cell differentiation," Advanced Drug Delivery Reviews, vol. 60, no. 2, pp. 215-228, 2008.

[85] K. Rezwan, Q. Z. Chen, J. J. Blaker, and A. R. Boccaccini, "Biodegradable and bioactive porous polymer/inorganic composite scaffolds for bone tissue engineering," Biomaterials, vol. 27, no. 18, pp. 3413-3431, 2006.

[86] W. S. Turner, E. Schmelzer, R. McClelland, E. Wauthier, W. Chen, and L. M. Reid, "Human hepatoblast phenotype maintained by hyaluronan hydrogels," Journal of Biomedical Materials Research Part B, vol. 82, no. 1, pp. 156-168, 2007.

[87] C. J. Bettinger, K. M. Cyr, A. Matsumoto, R. Langer, J. T. Borenstein, and D. L. Kaplan, "Silk fibroin microfluidic devices," Advanced Materials, vol. 19, no. 19, pp. 2847-2850, 2007.

[88] Y. M. Elçin, V. Dixit, and G. Gitnick, "Hepatocyte attachment on biodegradable modified chitosan membranes: in vitro evaluation for the development of liver organoids," Artificial Organs, vol. 22, no. 10, pp. 837-846, 1998.

[89] T. Ishii, K. Fukumitsu, K. Yasuchika, et al., "Effects of extracellular matrixes and growth factors on the hepatic differentiation of human embryonic stem cells," American Journal of Physiology, vol. 295, no. 2, pp. G313-G321, 2008.

[90] M. Schug, T. Heise, A. Bauer, et al., "Primary rat hepatocytes as in vitro system for gene expression studies: comparison of sandwich, Matrigel and 2D cultures," Archives of Toxicology, vol. 82, no. 12, pp. 923-931, 2008. 
[91] M. M. Stevens, H. F. Qanadilo, R. Langer, and V. P. Shastri, "A rapid-curing alginate gel systemml: utility in periosteumderived cartilage tissue engineering," Biomaterials, vol. 25, no. 5, pp. 887-894, 2004.

[92] A. D. Augst, H. J. Kong, and D. J. Mooney, "Alginate hydrogels as biomaterials," Macromolecular Bioscience, vol. 6, no. 8, pp. 623-633, 2006.

[93] S. Fang, Y.-D. Qiu, L. Mao, X.-L. Shi, D.-C. Yu, and Y.-T. Ding, "Differentiation of embryoid-body cells derived from embryonic stem cells into hepatocytes in alginate microbeads in vitro," Acta Pharmacologica Sinica, vol. 28, no. 12, pp. 1924-1930, 2007.

[94] J. J. Marler, J. Upton, R. Langer, and J. P. Vacanti, “Transplantation of cells in matrices for tissue regeneration," Advanced Drug Delivery Reviews, vol. 33, no. 1-2, pp. 165-182, 1998.

[95] H.-Y. Cheung, K.-T. Lau, T.-P. Lu, and D. Hui, "A critical review on polymer-based bio-engineered materials for scaffold development," Composites Part B, vol. 38, no. 3, pp. 291300, 2007.

[96] C. Liu, Z. Xia, and J. T. Czernuszka, "Design and development of three-dimensional scaffolds for tissue engineering," Chemical Engineering Research and Design, vol. 85, no. 7, pp. 1051-1064, 2007.

[97] M. Kellomäki and P. Törmälä, "Processing of resorbable poly- $\alpha$-hydroxy acids for use as tissue-engineering scaffolds," in Biopolymer Methods in Tissue Engineering, A. P. Hollander and P. V. Hatton, Eds., pp. 1-10, Humana Press, Totowa, NJ, USA, 2004.

[98] G. Chan and D. J. Mooney, "New materials for tissue engineering: towards greater control over the biological response," Trends in Biotechnology, vol. 26, no. 7, pp. 382392, 2008.

[99] H. Huang, S. Hanada, N. Kojima, and Y. Sakai, "Enhanced functional maturation of fetal porcine hepatocytes in threedimensional poly-L-lactic acid scaffolds: a culture condition suitable for engineered liver tissues in large-scale animal studies," Cell Transplantation, vol. 15, no. 8-9, pp. 799-809, 2006.

[100] J. L. Jiang, N. Kojima, L. Guo, et al., "Efficacy of engineered liver tissue based on poly-L-lactic acid scaffolds and fetal mouse liver cells cultured with oncostatin $\mathrm{M}$, nicotinamide, and dimethyl sulfoxide," Tissue Engineering, vol. 10, no. 9-10, pp. 1577-1586, 2004.

[101] S. Hanada, N. Kojima, and Y. Sakai, "Soluble factordependent in vitro growth and maturation of rat fetal liver cells in a three-dimensional culture system," Tissue Engineering Part A, vol. 14, no. 1, pp. 149-160, 2008.

[102] N.-J. Cho, M. Elazar, A. Xiong, et al., "Viral infection of human progenitor and liver-derived cells encapsulated in three-dimensional PEG-based hydrogel," Biomedical Materials, vol. 4, no. 1, Article ID 011001, 2009.

[103] M. Sokolsky-Papkov, K. Agashi, A. Olaye, K. Shakesheff, and A. J. Domb, "Polymer carriers for drug delivery in tissue engineering," Advanced Drug Delivery Reviews, vol. 59, no. 4-5, pp. 187-206, 2007.

[104] B. D. Ratner and S. J. Bryant, "Biomaterials: where we have been and where we are going," Annual Review of Biomedical Engineering, vol. 6, pp. 41-75, 2004.

[105] J. P. Desai, A. Pillarisetti, and A. D. Brooks, "Engineering approaches to biomanipulation," Annual Review of Biomedical Engineering, vol. 9, pp. 35-53, 2007.

[106] R. J. Zdrahala and I. J. Zdrahala, "Biomedical applications of polyurethanes: a review of past promises, present realities, and a vibrant future," Journal of Biomaterials Applications, vol. 14, no. 1, pp. 67-90, 1999.

[107] H. Ijima, T. Matsushita, K. Nakazawa, Y. Fujii, and K. Funatsu, "Hepatocyte spheroids in polyurethane foams: functional analysis and application for a hybrid artificial liver," Tissue Engineering, vol. 4, no. 2, pp. 213-226, 1998.

[108] H. Ijima, K. Nakazawa, H. Mizumoto, T. Matsushita, and K. Funatsu, "Formation of a spherical multicellular aggregate (spheroid) of animal cells in the pores of polyurethane foam as a cell culture substratum and its application to a hybrid artificial liver," Journal of Biomaterials Science, Polymer Edition, vol. 9, no. 7, pp. 765-778, 1998.

[109] J. Fukuda, R. Sakiyama, K. Nakazawa, et al., "Mass preparation of primary porcine hepatocytes and the design of a hybrid artificial liver module using spheroid culture for a clinical trial," International Journal of Artificial Organs, vol. 24, no. 11, pp. 799-806, 2001.

[110] K. Matsumoto, H. Mizumoto, K. Nakazawa, H. Ijima, K. Funatsu, and T. Kajiwara, "Hepatic differentiation of mouse embryonic stem cells in a three-dimensional culture system using polyurethane foam," Journal of Bioscience and Bioengineering, vol. 105, no. 4, pp. 350-354, 2008.

[111] E. S. Place, J. H. George, C. K. Williams, and M. M. Stevens, "Synthetic polymer scaffolds for tissue engineering," Chemical Society Reviews, vol. 38, no. 4, pp. 1139-1151, 2009.

[112] S. C. Baker, G. Rohman, J. Southgate, and N. R. Cameron, "The relationship between the mechanical properties and cell behaviour on PLGA and PCL scaffolds for bladder tissue engineering," Biomaterials, vol. 30, no. 7, pp. 1321-1328, 2009.

[113] D. E. Discher, P. Janmey, and Y.-L. Wang, "Tissue cells feel and respond to the stiffness of their substrate," Science, vol. 310, no. 5751, pp. 1139-1143, 2005.

[114] M. Bokhari, R. J. Carnachan, N. R. Cameron, and S. A. Przyborski, "Novel cell culture device enabling three-dimensional cell growth and improved cell function," Biochemical and Biophysical Research Communications, vol. 354, no. 4, pp. 1095-1100, 2007.

[115] P. Thevenot, W. Hu, and L. Tang, "Surface chemistry influences implant biocompatibility," Current Topics in Medicinal Chemistry, vol. 8, no. 4, pp. 270-280, 2008.

[116] P. Thevenot, A. Nair, J. Dey, J. Yang, and L. Tang, "Method to analyze three-dimensional cell distribution and infiltration in degradable scaffolds," Tissue Engineering Part C, vol. 14, no. 4, pp. 319-331, 2008.

[117] M. Dvir-Ginzberg, I. Gamlieli-Bonshtein, R. Agbaria, and S. Cohen, "Liver tissue engineering within alginate scaffolds: effects of cell-seeding density on hepatocyte viability, morphology, and function," Tissue Engineering, vol. 9, no. 4, pp. 757-766, 2003.

[118] H. Shin, S. Jo, and A. G. Mikos, "Biomimetic materials for tissue engineering," Biomaterials, vol. 24, no. 24, pp. 43534364, 2003.

[119] D. G. Anderson, J. A. Burdick, and R. Langer, "Smart biomaterials," Science, vol. 305, no. 5692, pp. 1923-1924, 2004.

[120] S. Duggal, K. B. Frønsdal, K. Szöke, A. Shahdadfar, J. E. Melvik, and J. E. Brinchmann, "Phenotype and gene expression of human mesenchymal stem cells in alginate scaffolds," Tissue Engineering Part A, vol. 15, no. 7, pp. 17631773, 2009.

[121] Y. Du, S.-M. Chia, R. Han, S. Chang, H. Tang, and H. $\mathrm{Yu}$, "3D hepatocyte monolayer on hybrid RGD/galactose 
substratum," Biomaterials, vol. 27, no. 33, pp. 5669-5680, 2006.

[122] M. P. Lutolf, J. L. Lauer-Fields, H. G. Schmoekel, et al., "Synthetic matrix metalloproteinase-sensitive hydrogels for the conduction of tissue regeneration: engineering cellinvasion characteristics," Proceedings of the National Academy of Sciences of the United States of America, vol. 100, no. 9, pp. 5413-5418, 2003.

[123] S. Zhang and C. E. Semino, "Design peptide scaffolds for regenerative medicine," Advances in Experimental Medicine and Biology, vol. 534, pp. 147-163, 2003.

[124] C. E. Semino, J. R. Merok, G. G. Crane, G. Panagiotakos, and S. Zhang, "Functional differentiation of hepatocyte-like spheroid structures from putative liver progenitor cells in three-dimensional peptide scaffolds," Differentiation, vol. 71, no. 4-5, pp. 262-270, 2003.

[125] L. Ferreira, J. M. Karp, L. Nobre, and R. Langer, "New opportunities: the use of nanotechnologies to manipulate and track stem cells," Cell Stem Cell, vol. 3, no. 2, pp. 136146, 2008.

[126] F. Loffredo and R. T. Lee, "Therapeutic vasculogenesis: it takes two," Circulation Research, vol. 103, no. 2, pp. 128-130, 2008.

[127] P. P. C. Poyck, G. Mareels, R. Hoekstra, et al., "Enhanced oxygen availability improves liver-specific functions of the AMC bioartificial liver," Artificial Organs, vol. 32, no. 2, pp. 116-126, 2008.

[128] M. Radisic, H. Park, F. Chen, et al., "Biomimetic approach to cardiac tissue engineering: oxygen carriers and channeled scaffolds," Tissue Engineering, vol. 12, no. 8, pp. 2077-2091, 2006.

[129] S. H. Oh, C. L. Ward, A. Atala, J. J. Yoo, and B. S. Harrison, "Oxygen generating scaffolds for enhancing engineered tissue survival,” Biomaterials, vol. 30, no. 5, pp. 757-762, 2009.

[130] J. T. Borenstein, E. J. Weinberg, B. K. Orrick, C. Sundback, M. R. Kaazempur-Mofrad, and J. P. Vacanti, "Microfabrication of three-dimensional engineered scaffolds," Tissue Engineering, vol. 13, no. 8, pp. 1837-1844, 2007.

[131] J. J. Moon, M. S. Hahn, I. Kim, B. A. Nsiah, and J. L. West, "Micropatterning of poly(ethylene glycol) diacrylate hydrogels with biomolecules to regulate and guide endothelial morphogenesis," Tissue Engineering Part A, vol. 15, no. 3, pp. 579-585, 2009.

[132] J. J. Moon and J. L. West, "Vascularization of engineered tissues: approaches to promote angiogenesis in biomaterials," Current Topics in Medicinal Chemistry, vol. 8, no. 4, pp. 300310, 2008.

[133] A. Carraro, W.-M. Hsu, K. M. Kulig, et al., "In vitro analysis of a hepatic device with intrinsic microvascularbased channels," Biomedical Microdevices, vol. 10, no. 6, pp. 795-805, 2008. 

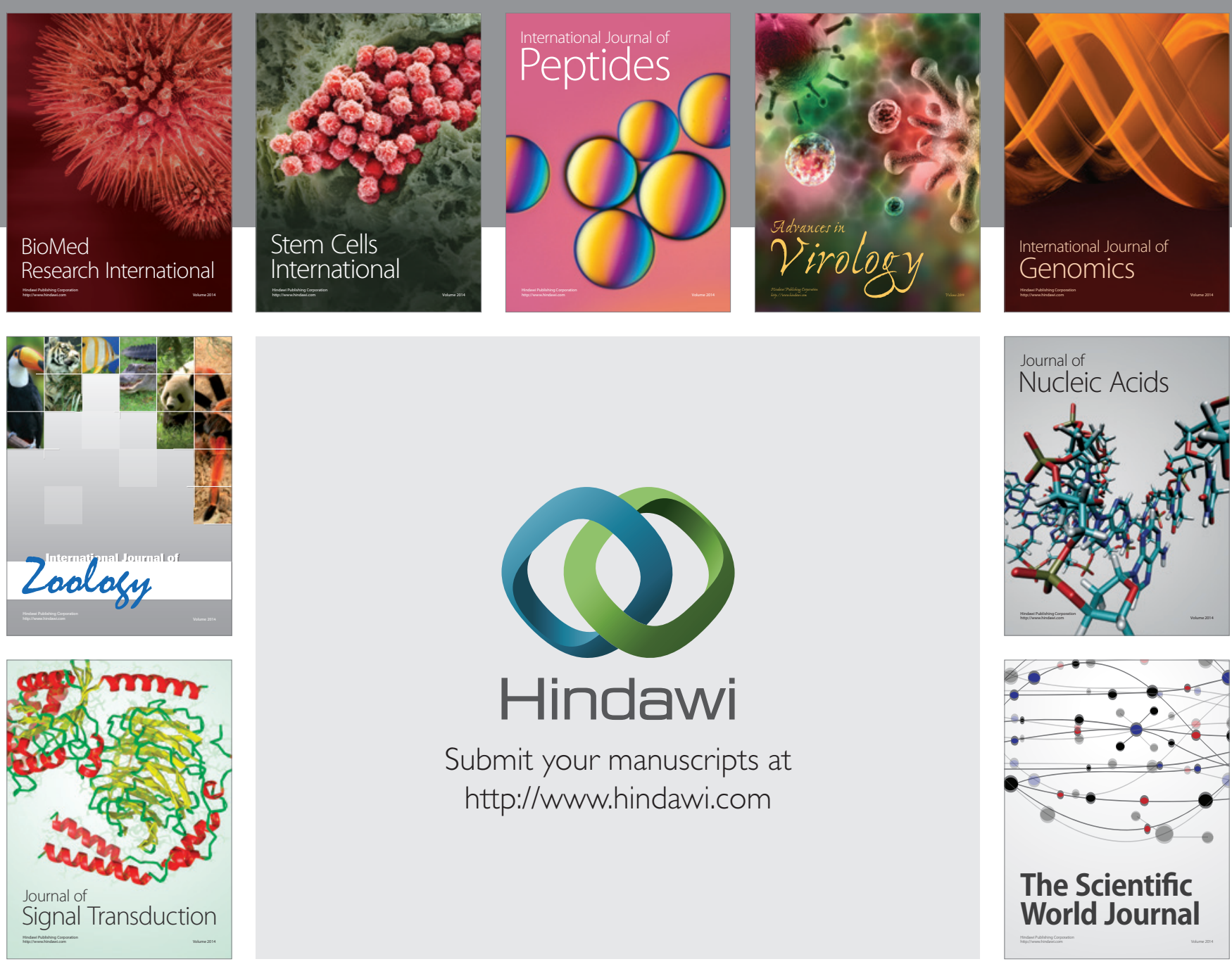

Submit your manuscripts at

http://www.hindawi.com
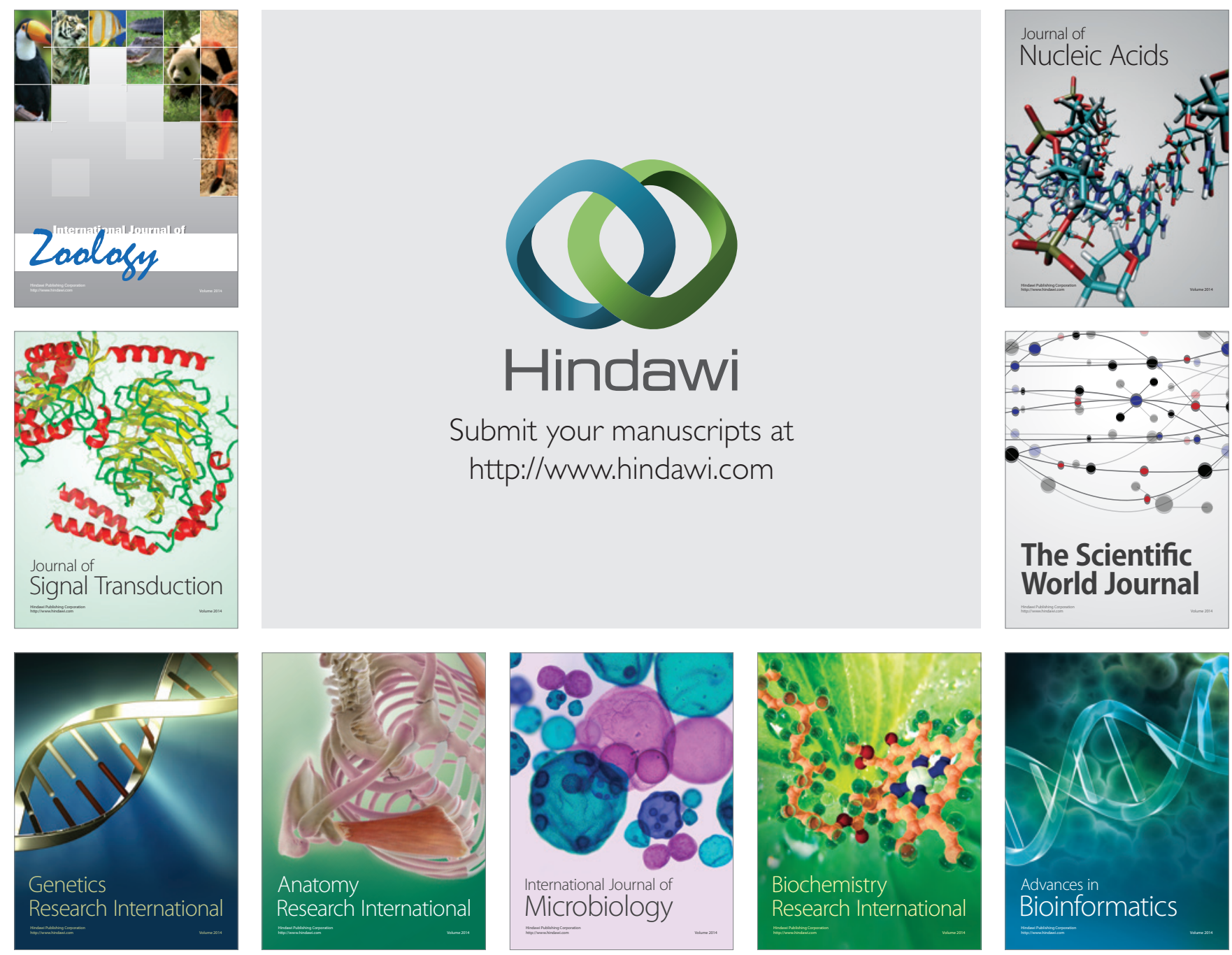

The Scientific World Journal
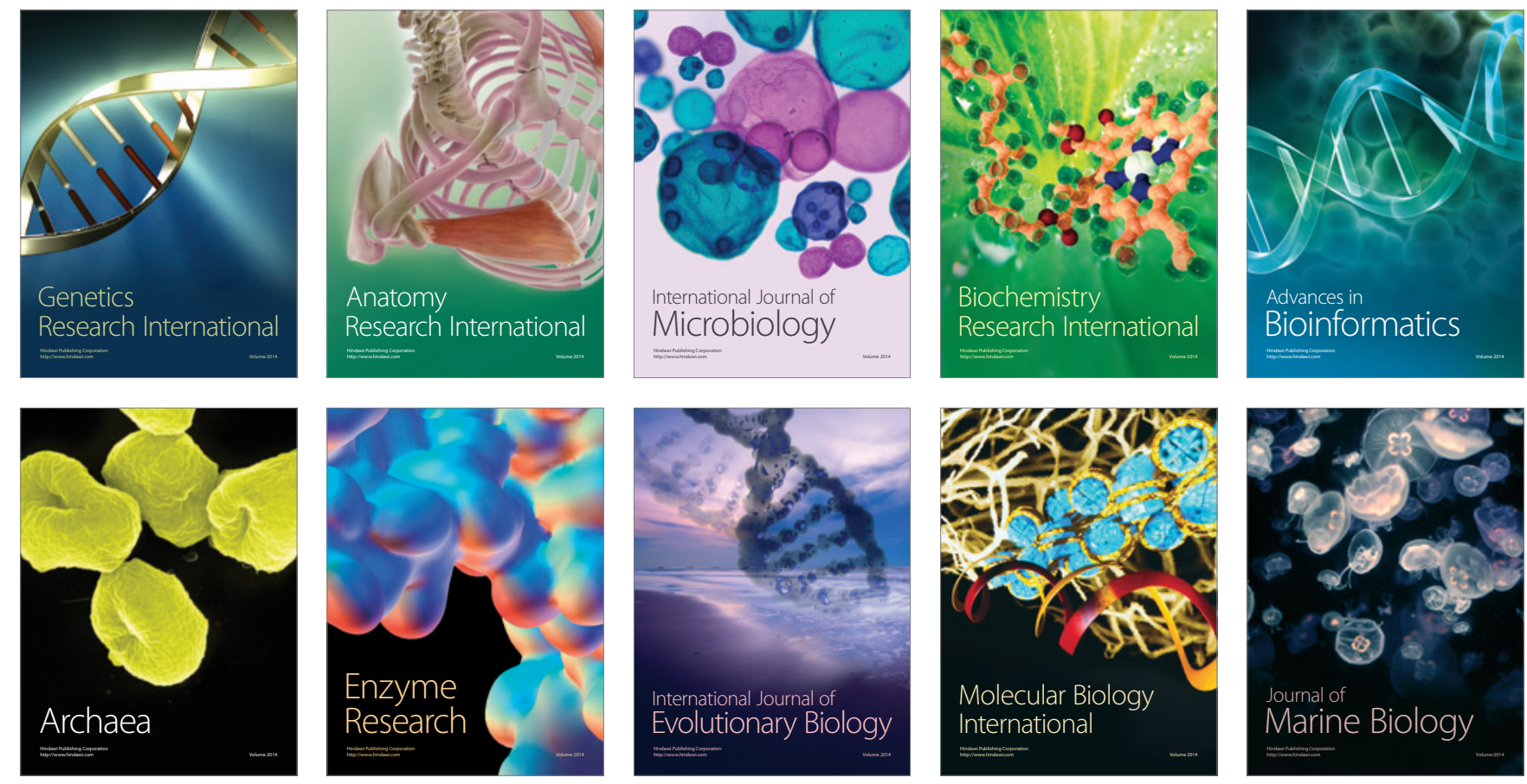